\title{
Past plant diversity changes and mountain tree species conservation
}

\author{
Rachid Cheddadi', N. Mhammdi ${ }^{2}$ and F. Sarmiento ${ }^{3}$
}

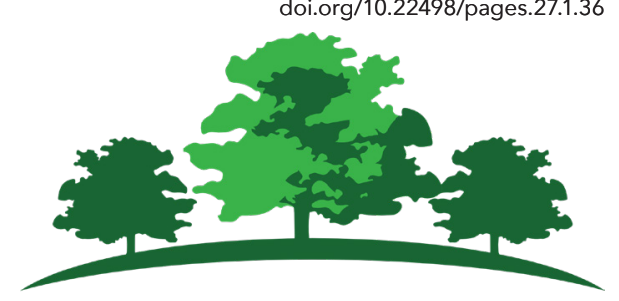

\section{Rabat, Morocco, 1-5 October 2018}

\section{Cuenca, Ecuador, 10-15 March 2019}

Two recent PAGES-endorsed conferences on "Past plant diversity changes and mountain tree species conservation" provided a great opportunity for scientists from different disciplines to discuss the issue of how the knowledge of plant diversity and ecosystem responses to past climate changes may help in managing species' persistence under ongoing global climate change. They were held under the umbrella of the ongoing project VULnerability of Populations under Extreme Scenarios (VULPES, vulpesproject.com, 20162020). The choice of locations was driven by the fact that both Morocco and Ecuador are hotspots of biodiversity with impressive numbers of endemic species, many of which are threatened with extinction. Both conferences were sponsored and introduced by the local authorities, which stated loudly and clearly the importance of organizing such meetings in their countries, where biodiversity is a national cause. In Ecuador, the protection of wildlife is now included in the constitution, and plants are protected by law.

\section{Scholars have clearly shown that under} current global climate change, many plant species should either adapt locally to persist in situ or migrate, if at all possible; otherwise, their modern range will be impacted to the extent of potential extinction. The geographical distribution of many mountain tree species is becoming more fragmented, often with a trend toward a reduction of the established areas. These tree species are considered by the IUCN Red List (iucnredlist.org) as endangered or threatened with extinction. The VULPES project focuses on a small number of these vulnerable mountain tree species (case studies) in Africa, China, and South America using a multi-disciplinary, multi-scale, and multi-species approach. Sessions at the two conferences were designed to fit this approach and to allow for, on the one hand, presentations of project results by the partners

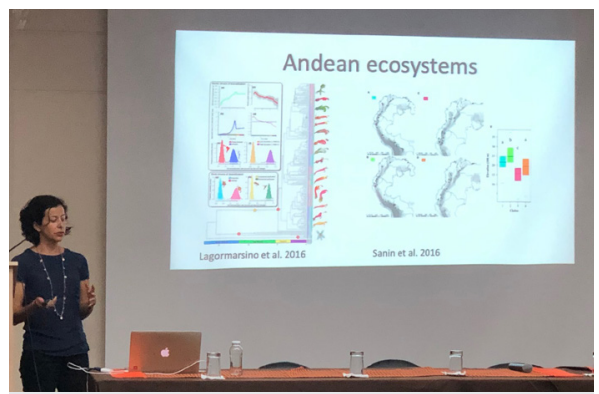

Figure 1: Selene Báez discusses the effects of current global environmental change on Neotropical montane forests (Cuenca 10-14 March, 2019). Photo credit: Elena Sarmiento to a wider community, and, on the other hand, input by members of this wider community through the presentation of their own results and open discussion.

In Rabat (vulpesproject.wixsite.com/biodiv2018), there were five sessions, each of which was introduced by an invited keynote speaker. Here we examined the relationship between past environmental changes and their impacts on plant species' diversity. The five sessions dealt with climate models and past climate variability (keynote Michel Crucifix, University of Louvain, Belgium), the species refugia during climatically unsuitable time periods (keynote Keith Bennett, University of St Andrews, UK), species migration and impacts on their genetic diversity (keynote Arndt Hampe, University of Bordeaux, France), modeling the species range (keynote Signe Normand, Aarhus University, Denmark) and, finally, the lessons we can draw from the past to help conserve plant species (keynote Steve Jackson, University of Arizona, USA). The conference was small (about 50 attendees) with brilliant presentations, which led to very interesting and in-depth discussions. In addition to the scientific attendees, Moroccan stakeholders were also present and clearly showed their interest in being involved in the process. The head of the Scientific Institute of Rabat, Dr. M. Fekhaoui, organized a tour of the local museum where hundreds of endemic plant and animal species from Morocco have been inventoried. The conference was followed by a two-day excursion to one of the largest and best preserved Atlas cedar forests, in the Ifrane National Park. The Atlas cedar is an endemic species to North Africa and considered to be endangered by the IUCN Red List. Twenty-five participants joined the excursion, which allowed for additional interesting discussions on many topics related to species conservation.

In Cuenca (vulpes-ecuador2019.com), in order to increase the discussion time among the 70 attendees, there was one "opening" and one "closing" keynote each day. The first day was introduced by Paul Valdes (University of Bristol, UK) on modeling past climates and the contribution of models to comprehending the mountain climate system. The closing keynote was David Neill (Universidad Estatal Amazónica, Puyo, Ecuador) with an open discussion on the endemic plant species from the sandstone summits (Andean tepuis) of the Cordillera del Cóndor in Peru and Ecuador. The second day was dedicated to plants' genetic diversity and long-term refugia. The introductory keynote was given by Mark Bush (Florida Institute of Technology, USA) on the microrefugia concept and how they may contribute to the future persistence of species in situ. Pierre Taberlet (University of Grenoble, France) provided the closing keynote on genetics and conservation biology within the context of Quaternary refugia. During the third day, three excellent choices of excursions were organized: (1) Ingapinca Inca archaeological site; (2) El Cajas National Park into the páramo, glacial lakes, and Andean (Polylepis) forests; and 3) El Collay community-protected forests and socioecological production landscape in the Azuay highlands. The last day of the conference was dedicated to practical scenarios for mountain forest conservation, with an introductory keynote by Veerle Vanacker (University of Louvain, Belgium) on landscape dynamics in tropical Andean ecosystems in response to natural and anthropogenic disturbances. Selene Báez (National Polytechnic School, Quito, Ecuador; Fig. 1) provided the last keynote of the conference on the effects of current global environmental change on Neotropical montane forests. This conference was marked by the participation of a large number of university students from Quito, Loja, and Cuenca, who took part actively through very interesting posters.

The discussions that took place at both conferences highlighted several interesting points: firstly, the size of the meeting (between 50 and 70 participants) was key to enabling extended presentations as well as in-depth discussions. Secondly, the multidisciplinary sessions with a joint focus on how we may contribute to better conservation of the biodiversity were highly appreciated by all participants, stakeholders, and students. These two conferences were concrete opportunities to exchange new ideas and learn new approaches, techniques, and concepts. One of the main conclusions is that the problem of preserving biodiversity cannot be tackled by one single discipline, concept, or approach. We need to combine our knowledge and work together through not only multi-disciplinary projects but also small multi-disciplinary meetings, where enough time is dedicated to in-depth discussions and direct exchanges with stakeholders and students.

\section{AFFILIATIONS}

University of Montpellier, France

${ }^{2}$ University Mohammed V of Rabat, Morocco ${ }^{3}$ University of Georgia, Athens, USA

\section{CONTACT}

Rachid Cheddadi: cheddadi.rc@gmail.com 